\title{
Acupuncture for Bone Disease Treatments, Modern Approaches
}

\section{Jin-Yu Che and Da-Yong Lu*}

School of Life Sciences, Shanghai University, Shanghai, China

*Corresponding Author: Da-Yong Lu, School of Life Sciences, Shanghai University, Shanghai, China.

DOI: 10.31080/ASOR.2022.05.0415
Received: December 30, 2021

Published: January 18, 2022

(C) All rights are reserved by Jin-Yu Che and

Da-Yong Lu.

\begin{abstract}
Acupuncture is widely used for bone disease treatments in China. However, it needs to cope with modern medicine. This editorial provides new acupuncture approaches in modern medicine.
\end{abstract}

Keywords: Acupuncture; Modern Medicine; Bone-Disease

\section{Introduction}

Human bone diseases ask for high-quality surgery, and effective food and drug treatments [1-16]. High levels of disease diagnosis, interventions and therapeutics call for excellent therapy for a lot of patients. Acupuncture is very important for bone disease treatments in China [16,17]. Acupuncture can support almost all areas of these bone treatments and recovery. This editorial provides new acupuncture approaches in modern medicine.

\section{Acupuncture History}

Acupuncture has a long history in China (> 2000 years) [18]. It was never interrupted across the history in China. It was as long as herbal medicine.

\section{Therapeutic Perfection}

Acupuncture is different from modern medicine and medical tradition of other countries. It can be very useful for human bone disease recovery and treatments. Entering into new era, we should promote acupuncture study and clinical application in a systematic way. Treatment schedules and protocols (temperature, treatment duration, electric-supportive and others) need to be customized [19-21] and cooperative ways (personalized medicine) [22-26].

\section{Conclusion}

In the future, more traditional Chinese medicine will be utilized in human disease treatments. In modern therapy, treatment protocols should be systematically studied.

\section{Bibliography}

1. Choudhary D and Alam A. "Anti-osteoporotic activity of bioactive compounds from Iris germanica targeting NK-Kappa B". EC Pharmacology and Toxicology 6.8 (2018): 665-678.

2. Lu DY and Shen Y. "Bone surgery, tissue and function repairs". EC Orthopedics 11.3 (2020): 1-2.

3. Lu DY., et al. "Bone disease treatments, math-therapeutic modality". EC Orthopedics 10.3 (2019): 140-143.

4. Lu DY and Che JY. "Bone disease treatment, an editorial". EC Orthopaedics 11.8 (2020): 143-145.

5. Che JY and Lu DY. "Bone disease treatment, future direction". EC Pharmacology and Toxicology 9.1 (2021): 7-8.

6. Negm SH. "The possible protective role of powder cuttlefish bone, crab shell and eggshell on osteoporotic rats". Journal of Food and Diary Science 9.10 (2018): 111-121.

7. Mobasheri A and Shakbael M. "Osteogenic effects of resveratrol in vitro: potential for the prevention and treatment of osteoporosis". Annals of the New York Academy of Sciences 1290 (2015): 59-66.

8. Lu DY and Xu B. "Bone metastasis treatment, major frontiers". Acta Scientific Orthopedics 4.7 (2021): 1-2.

9. Lu DY., et al. "How to improve the quality of pharmacotherapy for bone diseases". EC Orthopedics 10.6 (2019): 366-369. 
10. Lu DY and Xu B. "Bone metastasis treatment, major frontiers". Acta Scientific Orthopedics 4.7 (2021): 1-2.

11. Moore N and Slater GL. "Surgical technique update: Slater modification of minimally invasive brostrom reconstruction". EC Orthopedics 10.5 (2019): 308-314.

12. Lu DY and Che JY. "Pain alleviation for bone diseases". EC Orthopedics 12.7 (2021): 47-48.

13. Araujo JL. "The role of the orthopedic surgeon in preventing low back pain chronification". EC Orthopaedics 9.12 (2018): 809-812.

14. Lu DY and Che JY. "Bone disease treatments, technical advances". EC Orthopedics 11.10 (2020): 1-3.

15. Harsini SM and Oryan A. "Bone grafting and the materials for using in orthopaedics". EC Orthopaedics 9 (12 (2018): 822833.

16. Leung PC. "Traditional Chinese medicine in orthopaedicsproblems and future direction". Open Journal of Therapy Rehibilitations 2.1 (2014): 1-4.

17. Che JY and Lu DY. "Acupuncture for bone disease treatment". EC Orthopaedics 12.1 (2021): 15-16.

18. The Yellow Emperor's Internal Classic (Huang-Di-Nei-Jing, Emperor's Medical Experience).

19. Liu LL., et al. "Examination of the cellular mechanisms of leukocyte elevation by $10.6 \mu \mathrm{m}$ and $650 \mathrm{~nm}$ laser acupuncturemoxibustion". Laser in Medical Science 3 (2019): 263-271.

20. Li T., et al. "Comparing the efficacy of two different temperature stimulation in warm acupuncture on acute low back pain: a randomized controlled trial". Integrative Medicine Research 11 (2022): 100748.

21. Chen LS., et al. "The efficacy of jade moxibustion in knee osteoarthritisc". Medicine 99 (2020): 17.

22. Lu DY. "Personalized cancer chemotherapy, an effective way for enhancing outcomes in clinics". Woodhead Publishing, Elsevier, UK (2014).

23. Lu DY., et al. "Individualized cancer therapy, future approaches". Current Pharmacogenomics and Personalized Medicine 16.2 (2018): 156-163.

24. Lu DY., et al. "Individualized cancer therapy, what is the next generation?” EC Cancer 2.6 (2018): 286-297.

25. Damyanov C., et al. "Personalized treatment application in integrative oncology". Indian Journal of Research 7.1 (2018): 222-225.
26. Bertier G., et al. "Integrating precision cancer medicine into healthcare-policy, practice and research challenges". Genome Medicine 8 (2016): 108.

\section{Assets from publication with us}

- Prompt Acknowledgement after receiving the article

- Thorough Double blinded peer review

- Rapid Publication

- Issue of Publication Certificate

- High visibility of your Published work

Website: www.actascientific.com/

Submit Article: www.actascientific.com/submission.php

Email us: editor@actascientific.com

Contact us: +919182824667 